\title{
The role of the learning environment in adolescents' motivational development
}

\author{
Diana Raufelder $^{1}\left[\right.$. Stefan Kulakow ${ }^{1}[1]$
}

Accepted: 2 March 2021 / Published online: 17 March 2021

(c) The Author(s) 2021

\begin{abstract}
Past research has continuously shown that motivation in school declines across adolescence. To counteract potential declines in educational practice, the present study examines the motivational development of early and middle adolescent students within one school year and across two distinctive learning environments: a conventional teacher-directed learning environment and an individualized student-directed learning environment based on competency matrices. Based on a sample of $1153\left(M_{\text {age }}=13.97, S D=1.37,49 \%\right.$ girls $)$ students from grades 7 to 10 , latent change analyses were conducted to examine within-school year changes in general self-efficacy and intrinsic value. Significant interaction effects of age and learning environment suggest that motivational trajectories may diverge from the consistent motivational declines that have been demonstrated by past research. Students from both learning environments differed in their general self-efficacy, but not in their intrinsic value.
\end{abstract}

Keywords Motivation · Intrinsic motivation $\cdot$ Self-efficacy $\cdot$ Learning environments $\cdot$ Development

\section{Introduction}

For decades, empirical research has repeatedly shown that motivation in school decreases during adolescence. These declines have mostly been attributed to school transitions and to the lack of adaptivity of learning environments to maturing students (Eccles \& Midgley, 1989; Eccles \& Wigfield, 2020). In other words, students develop throughout adolescence in terms of physical and psychological maturation; however, their learning environments do not meet the needs of developing adolescents according to the stage-environment fit theory (Eccles \& Midgley, 1989; see Rosenzweig et al., 2019), which was recently integrated into situated expectancy-value theory (SEVT; Eccles \& Wigfield, 2020). While a vast body of research on motivation continuously exhibits determinants of fostering motivation in educational processes, a distinctive feature of students' experience in school, namely the learning environment, has been widely neglected (Kulakow \& Raufelder, 2020). The present study

Stefan Kulakow

stefan.kulakow@uni-greifswald.de

1 Department of Educational Science, University of Greifswald, Ernst-Lohmeyer-Platz 3, 17489 Greifswald, Germany has been conceptualized to address this important blind spot in educational research and simultaneously examine whether motivational declines can also be identified within a school year.

\section{Motivation and its development throughout adolescence}

According to SEVT, two key determinants of motivation are self-efficacy (i.e., success expectancy) and intrinsic value. Intrinsic value relates to the anticipated enjoyment of engaging in activities, while self-efficacy refers to expectancies of success or students' beliefs in their own ability to accomplish upcoming tasks.

Self-efficacy can be defined as the individual evaluation of capability to perform and succeed in certain behaviors (Bandura, 1997). Contrary to other capability beliefs, self-efficacy places a stronger focus on the individual conviction to be able to succeed rather than to evaluate individual prerequisites (Bong \& Skaalvik, 2003). While research on self-efficacy has mainly been domain specific, there has also been a growing research body concerning higher-order manifestations of self-efficacy that subsume domain specificity in favor of more overarching generalizations (e.g., Caroli, 2014). Bardach et al. (2019) 
conclude that differences in higher-order factors such as general self-efficacy might even represent stronger effects. This might be particularly true since domain-specific differences often cancel each other out. Self-efficacy has been shown to be beneficial for numerous educational outcomes such as increased achievement, persistence and effort, and self-regulation as well as reduced test anxiety (Tang \& Westwood, 2007; Kitsantas \& Zimmerman, 2008; Salami \& Ogundokun, 2009; Schnell et al., 2015; Hoigaard et al., 2015; Raufelder \& Ringeisen, 2016; Rossi et al., 2020) and is highly contextualized (Bandura, 1997). Individuals develop an "enduring interest in activities at which they feel efficacious and from which they derive self-satisfaction" (Bandura, 1997, p. 219). Longitudinal research on the development of self-efficacy has yielded quite ambiguous results. While some studies have exhibited a tendency of decline (Anderman et al., 1999; Urdan \& Midgley, 2003), others have found the opposite: continuous increases in self-efficacy with age (Zimmerman \& Martinez-Pons, 1990; Shell et al., 1995; Reeve \& Lee, 2014). However, whereas the former studies relied on general self-efficacy, the latter had a higher degree of specificity (i.e., reference to a certain class or subject).

Intrinsic value, which has often been called interest value, refers to "the anticipated enjoyment one expects to gain from doing the task for purposes of making choices and as the enjoyment one gets when doing the task" (Eccles \& Wigfield, 2020). Additionally, and similarly to self-efficacy, Wigfield \& Eccles (2020) propose that although these constructs are highly situation-specific, there are also hierarchies of these subjective task values that are predictive of students' task and activity choices. In that definition, it shares the properties of what Deci \& Ryan (2000, p. 70) refers to as intrinsic motivation- - the inherent tendency to seek out novelty and challenges, to extend and exercise one's capabilities, to explore, and to learn." However, it should be noted that despite the conceptual overlap of both constructs (i.e., intrinsic value and intrinsic motivation), they "come from distinct theoretical perspectives and so have different intellectual roots" (Eccles \& Wigfield, 2020, p. 73).

Person-oriented studies conducted within the framework of expectancy-value theory (EVT) have demonstrated that intrinsic value and success expectancy are highly correlated, although there is usually one group of students present that exhibit high expectancies but low intrinsic value (Lazarides \& Dicke et al., 2019; Lazarides \& Dietrich et al., 2019). While there have generally been high stabilities of these patterns in these studies, numerous students have changed to more or less adaptive profiles throughout adolescence. Consequently, we can assume that there are substantial interindividual differences in the association of intrinsic value and self-efficacy.

\section{Learning environments as distinctive precursors of motivation}

In the shift from EVT to SEVT, Eccles et al. (2020) have highlighted the role of context in educational trajectories. In this way, they more coherently incorporate aspects that have previously been limited to stage environment fit theory (Eccles \& Midgley, 1989; Eccles, 1993). Thus, it is assumed that the educational context with various features (e.g., socializers' beliefs, activity characteristics and demands, possible activities) influences students' expectancy and value beliefs. More specifically, it is assumed that the majority of motivational declines that have been shown by empirical research can be attributed to a mismatch of the individual needs of students in specific phases of their development and the educational context that should foster learning processes (Eccles \& Midgley, 1989). One core problem is that in conventional TDL environments, there is a strict focus on normative comparisons of students' academic performance rather than on individual development. Moreover, these rather controlling learning environments are established in a time in which adolescents continuously seek for more room for independent decision-making, mainly manifested in the need of autonomy. Accordingly, Rosenzweig and colleagues (2019, p. 624) stated that such "school environment changes can negatively impact many students' expectancies and values for various academic tasks and subject areas" (Rosenzweig et al., 2019, p. 624).

Interestingly, the majority of empirical motivational research refers to the term adaptivity with regard to students' tendencies to adapt to their learning environments. Thus, adaptive motivation usually refers to students who demonstrate high values of motivation, whereas maladaptive motivation refers to those who demonstrate low values (e.g., Kolić-Vehovec et al., 2008; Collie \& Martin, 2017; Lazarides \& Dicke et al., 2019). However, if we consider the theoretical backgrounds that (a) "lack of fit between children at this stage of life and the classroom environments they experience" (Eccles \& Midgley, 1989, p. 174), (b) "caregiving environments nonetheless strongly affect these intrinsic properties to learn" (Ryan \& Deci, 2017, p. 352), and (c) "efficacy beliefs [...] are differentiated across domains and contexts" (Zimmerman, 1997, p. 216) - it becomes apparent that contexts, such as specific learning environments may be more or less adaptive to students' needs, which in turn may have repercussions on their motivation.

Furthermore, features of the educational context (i.e., adaptive prerequisites) are usually captured by aggregated classroom and school variables (Lüdtke et al., 2008; Marsh et al., 2012; Bardach et al., 2020). For example, Morin 
et al. (2014) demonstrated that aggregated classroom climate (i.e., classroom goals, challenge, teacher caring) had positive effects on students' self-efficacy. However, this line of empirical research is built on the assumption that all learning environments are basically the same and differ only with regard to the magnitude of those climate variables. In contrast, a study has shown that differences between learning environments can persist even after controlling for classroom-level differences (Kulakow, 2020b).

However, the question that arises is-when are learning environments adaptive? From our point of view, a major hindrance to achieving adaptivity is the dependence of conventional learning environments on the teacher: in traditional teacher-directed learning environments, teachers have to simultaneously determine learning goals, select appropriate material, choose methods to enhance variability, evaluate performance, and provide a supportive climateat best, for each student individually. It is no wonder that many teachers prefer ability-grouped classes, because these help teachers address their students' needs more adequately (Chorzempa \& Graham, 2006). In that way, Eccles and colleagues (1991, p. 533) state that particularly after the transition from elementary schools to secondary schools, students face "greater emphasis on teacher control and discipline, a less personal and positive teacher-student relationship, and fewer opportunities for student decision-making, choice, and self-management." In other words, students' basic needs for autonomy, competence and social relatedness-as stated in self-determination theory (SDT; Deci \& Ryan, 1985)—are less satisfied in TDL in secondary schools. However, satisfying adolescents' needs is critically important for maintaining adolescents' motivation in school (Gnambs \& Hanfstingl, 2016; Ryan \& Deci, 2017). Supplemented with increases in whole-class instruction and between-class ability grouping, which is typical for the traditional teacher-directed learning (TDL) environments that still endure and dominate in-class learning since decades, it is questionable how such learning environments can be adaptive to students' needs.

\section{Student-directed learning environments on the basis of competency matrices}

In recent years, educational practice has seen an influx of alternative learning environments that challenge traditional views of how learning and instruction typically work. Generally, these learning environments are subsumed under the umbrella term of student directedness (Knowles, 1975). These student-directed learning (SDL) environments aim to be adaptive to students' needs through instructional practice that tries to tailor learning processes more individually (Baeten et al., 2010): by taking students' interests into consideration, providing flexible learning conditions and individualized learning objectives and offering phases in which students are responsible for their own learning students' need of autonomy can be satisfied (Benware \& Deci, 1984; Vansteenkiste et al., 2004; Benita et al., 2014). By providing opportunities for self-assessment, offering feedback (suggestions of specific steps for improvement) that supports actions, and including students when setting learning objectives, students' need of competence can be satisfied (Pianta et al., 2003; Hattie, 2009; Niemiec \& Ryan, 2009; see Schweder \& Raufelder, 2021a, b). One such studentdirected learning (SDL) environment that is receiving increasing attention in Germany builds its instruction and learning processes on the work with competency matrices. In this way, as in many other forms of classroom organization, the instructional process is partly decoupled from the teacher in such a way that teachers can support individual students without stopping or blocking learning processes for other students (Kulakow, 2020b). While competency matrices have a long history of being used as a means for assessment and evaluation (Stevens et al., 2013; Lesmond et al., 2017), they have also recently been discovered as a means for instruction and the coordination of learning processes. Initially, students' initial competence level is determined across different subjects and across different subject domains (i.e., competence domains). Schools handle this determination of the initial position within the competency matrix differently: they either conduct some form of summative assessment which should approximate the zone of proximal development (Vygotsky, 1978) or they determine the initial position by means of students' self-assessment to encourage metacognitive thinking. Depending on that initial sub-competence level, students are enabled to access material that helps them to develop that respective competence following a task-based learning approach (Schweder et al., 2019; Kulakow, 2020b). Subsequently, depending on the tasks and sub-competence levels at hand, they engage in evaluation with respective solutions or with the support of peers and teachers. Implicitly, this learning environment thereby follows the cyclical model of self-regulation (Zimmerman, 2000). In that learning environment, instruction is generally independent of the teacher, who can in turn focus on individual support, classroom management and a general positive climate, which fosters students' need satisfaction of social relatedness.

However, there is limited research that contrasts students' motivational development in different learning environments. Prior research that compared students in SDL and TDL environments is mostly based on cross-sectional designs and mean value differences between groups (Schweder, 2019; Schweder et al., 2019; Kulakow, 2020b). These studies have shown that students in SDL report higher mean values of autonomy, interest, flow, elaboration, persistence, mastery goals and positive emotions as well as higher self-efficacy and academic self-concept compared to 
students in TDL (Kulakow, 2020a; b; Schweder \& Raufelder, 2021a, b; Schweder et al., 2020). However, none of these studies examined motivational trajectories over time. The present study was conceptualized to fill this research gap.

\section{Hypotheses}

Based on SEVT and the empirical results outlined above, the present study examines the following hypotheses:

H1: Generally, there is a negative development of intrinsic value and self-efficacy from $\mathrm{T} 1$ to $\mathrm{T} 2$, since students' intrinsic motivation and self-efficacy tend to decrease during adolescence (Anderman et al., 1999; Urdan \& Midgley, 2003; Otis et al., 2005; Gnambs \& Hanfstingl, 2016) and during a school year (Corpus et al., 2009).

H2: Changes in students' self-efficacy are associated with changes in their intrinsic value.

H3: Age and group membership (SDL vs. TDL) predict the change in both intrinsic value and self-efficacy.

H4: The interaction of age and group membership additionally functions as a predictor of the changes in both selfefficacy and intrinsic value.

\section{Methods}

\section{Sample}

The first round of data collection took place in the 2015 winter term of the German school year. In this first round, 1153 adolescent students aged 12 to 18 years from grades 7 to $10\left(M_{\text {age }}=13.97, \mathrm{SD}=1.37,49 \%\right.$ girls $)$ from six secondary schools in the federal states of Berlin, MecklenburgWest Pomerania, North Rhine-Westphalia, and SchleswigHolstein were asked to complete the survey instruments. The second round of data collection took place in the 2016 summer term, wherein 775 adolescent $\left(M_{\text {age }}=14.27\right.$, SD $=1.25,49 \%$ girls) students from the original sample were surveyed again. The dropout rate between both points of measurement was $22.8 \%$.

Three schools were purposely chosen that have an individualized SDL environment with competency matrices at their core. In the pool of potential schools, we only considered those that met the following criteria: (1) The use of competency matrices as the main instructional practice has been present in the school for so long that study participants have only been exposed to this learning environment in their secondary school lives. (2) Competence matrices are used in all major subjects (i.e., German, mathematics, second language). (3) Apart from specific teacher interventions, students can generally decide for themselves which subjects they want to work on.
Based on these criteria, only three schools were eligible, all of which are urban low-track and mixed-track schools $\left(N_{\text {classes }}=36\right)$. Since no rural and no high-track schools are present in this sample, for the comparison group - the TDL group-a restricted random sample was chosen; this also excluded rural and low-track schools to achieve comparability $\left(N_{\text {classes }}=21\right)$. These schools have a traditional TDL environment at the core of their instructional practices.

\section{Procedure}

To comply with school and privacy laws as well as with ethical standards (American Psychological Association, 2002), a strict procedure was adhered to. First, since in Germany the collection of data in schools has to be approved by the government, permission to conduct the study was granted by the Ministry of Education, Science, and Culture of the federal state of Mecklenburg-Vorpommern, the Senate Administration for Education, Youth, and Family of the federal state of Berlin, the Ministry of Education and Science of the federal state of SchleswigHolstein, and the Ministry of Schools and Education of the federal state of North Rhine-Westphalia. Second, the schools were approached. Third, letters were distributed to students and teachers explaining the goals of the study, the voluntary nature of participation, and the assurance of anonymity. To ensure this anonymity in the longitudinal assessment, students were first pseudonymized. For that, random codes were generated for each student and were stored by the principal investigator. After the second wave of data collection, these lists containing pseudonyms and students' name were deleted.

On the day of data collection, two research assistants were present throughout the survey. They repeated the goals, the voluntary nature of participation, and the data protection to the students, and they then explained how to use the questionnaire, particularly the Likert scales. Moreover, if necessary, they answered any questions about the nature of the questions and explained any ambiguous items.

\section{Measures}

\section{Self-efficacy}

Using the German version of the general self-efficacy scale (Jerusalem \& Schwarzer, 1999), students answered 10 items (e.g., "I can find a solution for every problem") on a 4-point Likert scale ranging from 1 ("not true") to 4 ("exactly true") to evaluate their self-efficacy. McDonald's Omega indicated good reliability $\left(\omega_{\mathrm{T} 1}=0.86\right.$.; $\left.\omega_{\mathrm{T} 2}=0.87\right)$. 


\section{Intrinsic value}

Using the version of the Academic Self-Regulation Questionnaire (Ryan \& Connell, 1989) adapted and validated for German students (Müller et al., 2007), intrinsic value was measured with five items on a 5-point Likert scale ranging from 1 ("strongly disagree") to 5 ("strongly agree"; e.g., "I work and learn in class because it is enjoyable"). The scale exhibited a good reliability $\left(\omega_{\mathrm{T} 1}=0.86, \omega_{\mathrm{T} 2}=0.86\right)$. In the absence of suitable validated and established measurement instruments for German students, we operationalized intrinsic value using intrinsic motivation.

\section{Statistical analyses}

All statistical analyses were performed with Mplus 8.1 (Muthén \& Muthén, 1998-2017) using the robust maximum likelihood (MLR) estimator. Because the data of the present sample underlie a nested structure (students in classes), the complex modeling procedure (type $=$ complex) was followed, which corrects the estimated standard errors for nested structure in data (Hox, 2002).

Initially, descriptive statistics and measurement invariance tests were estimated. Subsequently, structural equation models were conceptualized to test the hypotheses. With latent change models, both intraindividual and interindividual differences in change over time can be identified (Steyer et al., 1997; Steyer et al., 2000; Hamagami \& McArdle, 2001; McArdle, 2009). The Steyer et al. (1997) parametrization was utilized where the latent variables at $\mathrm{T} 1$ were measured using the indicators at $\mathrm{T} 1$ and $\mathrm{T} 2$ and the latent differences (i.e., $\Delta$ intrinsic value, $\Delta$ self-efficacy) were identified using solely the indicators at $\mathrm{T} 2$.

The analyses are built on a two-step procedure: First, to examine the change and general development of intrinsic value and self-efficacy from $\mathrm{T} 1$ to $\mathrm{T} 2$, an unconditional latent change model was estimated solely for intrinsic value and self-efficacy. Second, a conditional latent change model with intrinsic value and self-efficacy in one model was designed to detect the associations between the changes in intrinsic value and self-efficacy over time. Furthermore, the group variable, which distinguishes between students from SDL environments and students from TDL environments, was included as the predictor variable of the change in intrinsic value and self-efficacy. Since the sample is constituted of 7 th to 10th graders, age was also included as a potential predictor variable of the change in intrinsic value and self-efficacy. Finally, an interaction term of age and group was included as a predictor variable to test whether both age and group membership explain the change in students' intrinsic value and self-efficacy. To counteract a potential inflation of type I error rate, all significance values were adjusted with the
Benjamini and Hochberg (1995) procedure, which control the false discovery rate of the hypotheses.

As is common in statistical analyses, the following parameters have been considered to identify the quality of each structural equation model (e.g., Hu \& Bentler, 1999; Schweizer, 2010; West et al., 2012): Besides the $\chi^{2}$-statistic that is sensitive to sample size (Marsh et al., 2005; Kline, 2016), the comparative fit index (CFI), the root mean square error of approximation (RMSEA), and the standardized root mean square residual (SRMR) were used as indicators. An acceptable fit to the data is reflected by CFI values greater than 0.90 and RMSEA and SRMR values lower than. If the CFI value is greater than 0.95 and the RMSEA and SRMR values are lower than 0.06 and 0.08 respectively, the models reflect good fit to the data.

Of the 1153 cases used in the study, 393 (34\%) were affected by missing data. Across the 34 observed variables, missingness varied between $0.00 \%$ and $32.78 \%$. Due to the extensive critique of traditional techniques of removing all missing data (listwise deletion) or mean imputation (Little \& Rubin, 1987, 1989; Schafer \& Graham, 2002), the presented analyses are based on the full information maximum likelihood (FIML) approach that, in contrast to these traditional techniques, reduces bias. More precisely, maximum likelihood estimation increases the precision of the parameter estimates while simultaneously maintaining statistical power. The FIML approach was conducted under the missing at random assumption (Rubin, 1987).

\section{Results}

Initially, latent bivariate correlations between the interest and self-efficacy measures and their descriptive statistics were conducted (see Table 1).

In the next step, measurement invariance testing for all variables was conducted following a stepwise procedure as recommended by Brown (2015). The fit indices of the subsequent models (see Table 2) were all below the thresholds recommended by Chen (2007), which implies strong factorial invariance. These guidelines state that a more restricted model replicates the data better if $\chi^{2}$ is insignificant (Satorra $\&$ Bentler, 2001) and that models are favored if $\triangle$ RMSEA $\leq .015, \Delta \mathrm{CFI} \leq .010$, and $\Delta$ SRMR $\leq .010$ (Chen, 2007). Strong factorial invariance is a precondition of conducting latent change models.

\section{Latent change models}

To test $\mathrm{H} 1$ and $\mathrm{H} 2$, an unconditional latent change model was used to investigate the change in intrinsic value and self-efficacy from $\mathrm{T} 2$ to the initial state (T1). This unconditional latent change model (see Fig. 1) showed a good model 
Table 1 Bivariate latent correlations, means, range, standard deviations, skewness (SE), kurtosis (SE)

\begin{tabular}{|c|c|c|c|c|c|c|c|c|c|c|}
\hline & Mean & SD & Range & Skewness (SE) & Kurtosis (SE) & 2 & 3 & 4 & 5 & 6 \\
\hline \multicolumn{11}{|l|}{ Time 1} \\
\hline 1 Intrinsic value & 2.82 & 0.85 & $1-5$ & $0.72(0.07)$ & $-1.48(0.14)$ & $0.48^{*}$ & $0.64 *$ & $0.40 *$ & $-0.08 *$ & $-0.09 *$ \\
\hline 2 Self-efficacy & 2.67 & 0.53 & $1-4$ & $0.05(0.07)$ & $-.07(0.14)$ & & $0.29 *$ & $0.62 *$ & 0.01 & $-0.24 *$ \\
\hline \multicolumn{11}{|l|}{ Time 2} \\
\hline 3 Intrinsic motivation & 2.79 & 0.86 & $1-5$ & $-0.10(0.09)$ & $-0.22(0.18)$ & & & $0.40^{*}$ & -0.05 & -0.03 \\
\hline 4 Self-efficacy & 2.65 & 0.54 & $1-4$ & $-.23(0.09)$ & $0.47(0.18)$ & & & & 0.02 & $-0.17 *$ \\
\hline \multicolumn{11}{|l|}{ Predictor variables } \\
\hline 5 Age & 13.97 & 1.37 & $11-18$ & & & & & & & 0.13 \\
\hline 6 Group & & & $0-1$ & & & & & & & \\
\hline
\end{tabular}

${ }^{*} p<0.05$; The correlation coefficients are standardized; group: $0=$ students from student-centered learning environments, $1=$ students from teacher-directed learning environments

Table 2 Summary of results for tests of longitudinal measurement invariance

\begin{tabular}{|c|c|c|c|c|c|c|c|c|c|c|}
\hline Model & $d f$ & $\chi^{2}$ & $p$ & CFI & RMSEA & $90 \% \mathrm{CI}$ & SRMR & $\Delta \mathrm{CFI}$ & $\Delta$ RMSEA & $\Delta \mathrm{SRMR}$ \\
\hline \multicolumn{11}{|l|}{ Intrinsic value } \\
\hline 1 Configural MI & 34 & 150.07 & $<0.001$ & 0.97 & 0.05 & [0.05-0.06] & 0.04 & - & - & - \\
\hline 2 Metric MI & 38 & 161.49 & $<0.001$ & 0.97 & 0.05 & {$[0.05-0.06]$} & 0.04 & 0.002 & 0.001 & 0.006 \\
\hline 3 Scalar MI & 42 & 173.37 & $<0.001$ & 0.96 & 0.05 & [0.04-0.06] & 0.04 & 0.002 & 0.001 & 0.004 \\
\hline \multicolumn{11}{|l|}{ Self-efficacy } \\
\hline 1 Configural MI & 169 & 432.23 & $<0.001$ & 0.95 & 0.04 & [0.03-0.04] & 0.04 & - & - & - \\
\hline 2 Metric MI & 178 & 444.05 & $<0.001$ & 0.95 & 0.04 & [0.03-0.04] & 0.04 & 0 & 0.001 & 0.003 \\
\hline 3 Scalar MI & 186 & 458.13 & $<0.001$ & 0.95 & 0.04 & [0.03-0.04] & 0.04 & 0.001 & 0 & 0 \\
\hline
\end{tabular}

MI measurement invariance

fit: $\chi^{2}(410)=796.36, p<0.001 ; \mathrm{CFI}=0.96$, RMSEA $=0.03(0.03-0.03) ;$ SRMR $=0.04)$. In contrast to H1, the mean values of the change parameters show that there is no significant development of intrinsic value and self-efficacy over time: Neither intrinsic value's mean $\left(\Delta M=-0.03, p_{B H}\right.$ $=0.321 ; \sigma^{2}=0.19, p_{B H}=0.002$ ), nor self-efficacy's mean $\left(\Delta M=-0.01, p_{B H}=0.641 ; \sigma^{2}=0.19, p_{B H}=0.002\right)$ significantly decreased from T1 to T2. However, the significant variances in the changes indicate substantial interindividual differences in the intraindividual changes. Furthermore, the variance of the initial state of intrinsic value is significant $\left(\sigma^{2}=0.57, p_{B H}=0.002\right)$ as is the initial state of self-efficacy $\left(\sigma^{2}=0.23, p_{B H}=0.002\right)$, which indicates that the students in this sample differed significantly in terms of intrinsic value and self-efficacy at T1. Figure 1 shows all significant associations between the initial state of intrinsic value and selfefficacy and their development over time. The results show that the initial state value of intrinsic value is significantly associated with the initial state value of self-efficacy $(\phi=$ $\left.0.18, \mathrm{SE}=0.02, p_{B H}=0.002\right)$. The initial state value of intrinsic value is significantly associated with the change score of intrinsic value $\left(\phi=-0.21, \mathrm{SE}=0.03, p_{B H}=0.002\right)$ but not with the change score of self-efficacy $(\phi=-0.03$,
$\mathrm{SE}=0.02, p_{B H}=0.212$ ). In turn, the initial state value of self-efficacy is significantly associated with both the change score of intrinsic value $\left(\phi=-0.07, \mathrm{SE}=0.23, p_{B H}=0.002\right)$ and the change score of self-efficacy $(\phi=-0.09, S E=0.01$, $\left.p_{B H}=0.002\right)$. In line with $\mathrm{H} 2$, the changes in intrinsic value and self-efficacy between $\mathrm{T} 1$ and $\mathrm{T} 2$ are positively associated $\left(\phi=0.11, \mathrm{SE}=0.02, p_{B H}=0.002\right)$.

To test $\mathrm{H} 3$ and $\mathrm{H} 4$, a conditional latent change model with age, the grouping variable (i.e., learning environment) and the interaction term of age and group variable as predictor variables was conceptualized (see Fig. 2). This conditional latent change model also showed a good model fit: $\chi^{2}(488)=926.21, p<0.001 ; \mathrm{CFI}=0.96, \mathrm{RMSEA}=0.03$ (0.03-0.03); SRMR $=0.04)$. Confirming H3, the results show that age $\left(\beta=0.16, \mathrm{SE}=0.08, p_{B H}=0.045\right)$ and group membership $\left(\beta=1.42, \mathrm{SE}=0.52, p_{B H}=0.009\right)$ positively predict the change in intrinsic value. However, only group membership ( $\left.\beta=1.45, \mathrm{SE}=0.47, p_{B H}=0.004\right)$ significantly predicts the change in self-efficacy; age does not ( $\beta=0.11$, $S E=0.07, p_{B H}=0.145$ ).

Furthermore, and in line with $\mathrm{H} 4$, the interaction term predicts the changes in both intrinsic value $(\beta=-1.43$, SE $\left.=0.54, p_{B H}=0.011\right)$ and self-efficacy $(\beta=-1.43, \mathrm{SE}=$ 
Fig. 1 Unconditional latent change model of the development of self-efficacy and intrinsic value from $\mathrm{T} 1$ to $\mathrm{T} 2 ; \mathrm{t} 1=$ Time 1; $\mathrm{t} 2=$ Time2; Significant effects are shown as unstandardized coefficients (B) in boldface and standardized coefficients $(\beta)$ in second position; solid pathways are significant at $p<0.05$

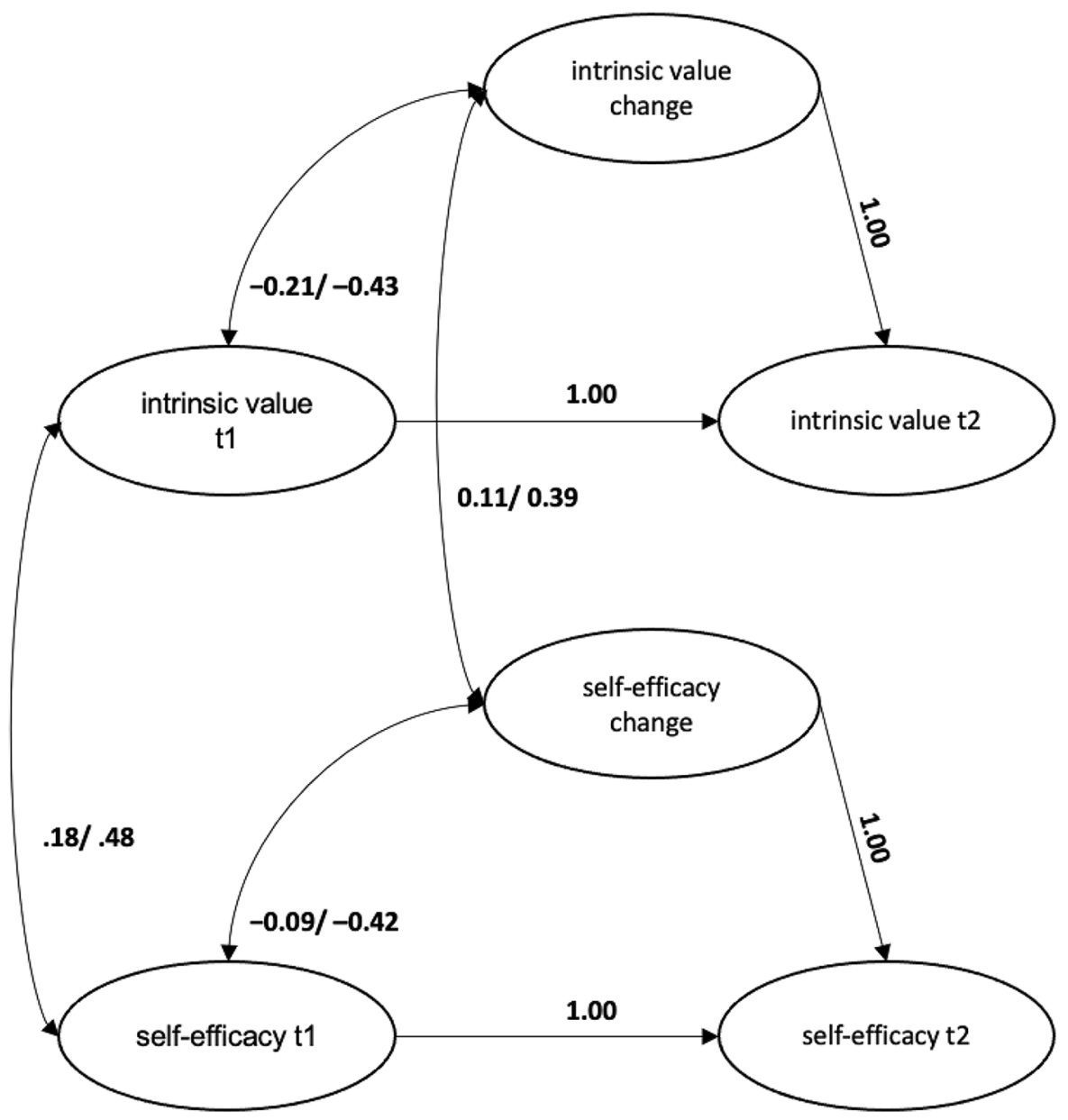

$0.51, p_{B H}=0.008$; see Figs. 3 and 4). As shown in Figs. 3 and 4 , the older the students in SDL are, the higher the changes (decline) in both intrinsic value and self-efficacy are. In TDL it is exactly the opposite: the older the students in TDL are, the smaller the changes in both intrinsic value and self-efficacy are.

\section{Discussion}

Based on SEVT, the present study was intended to examine the longitudinal development of intrinsic value and selfefficacy in the course of adolescence and across different learning environments. To deepen our understanding of motivational trajectories, the study investigated how different learning environments might counteract the motivational declines that have been regularly revealed in prior research (Otis et al., 2005; Gnambs \& Hanfstingl, 2016).

$\mathrm{H} 1$ proposed a decline in both intrinsic value and selfefficacy within a school year for all age groups. This hypothesis is not supported by our data. Overall, our data indicates stability of both variables. However, significant variances indicate that there are indeed students whose intrinsic value and self-efficacy decline within a school year. However, these students are complemented by others who exhibited either increases or stability in intrinsic value and self-efficacy, which in turn cancel each other out. With regard to self-efficacy, this finding adds to prior research that has found both increase and decrease during adolescence (Zimmerman \& Martinez-Pons, 1990; Shell et al., 1995; Shell et al., 1995; Anderman et al., 1999; Urdan \& Midgley, 2003; Reeve \& Lee, 2014). However, this finding directly contradicts research that has shown that intrinsic value continuously decreases (Otis et al., 2005; Corpus et al., 2009; Gnambs \& Hanfstingl, 2016). Potential reasons might lie in the sample of our study: While many other studies were conducted on complete random samples, our dataset consists only of students from lower- and mixed-track secondary schools. To our knowledge, there are only a few studies that investigated motivational differences across different educational tracks (e.g., Schaffner et al., 2016). For example, a longitudinal study on intrinsic reading motivation among German secondary students revealed a systematical decrease that was similar across school tracks (Miyamoto 


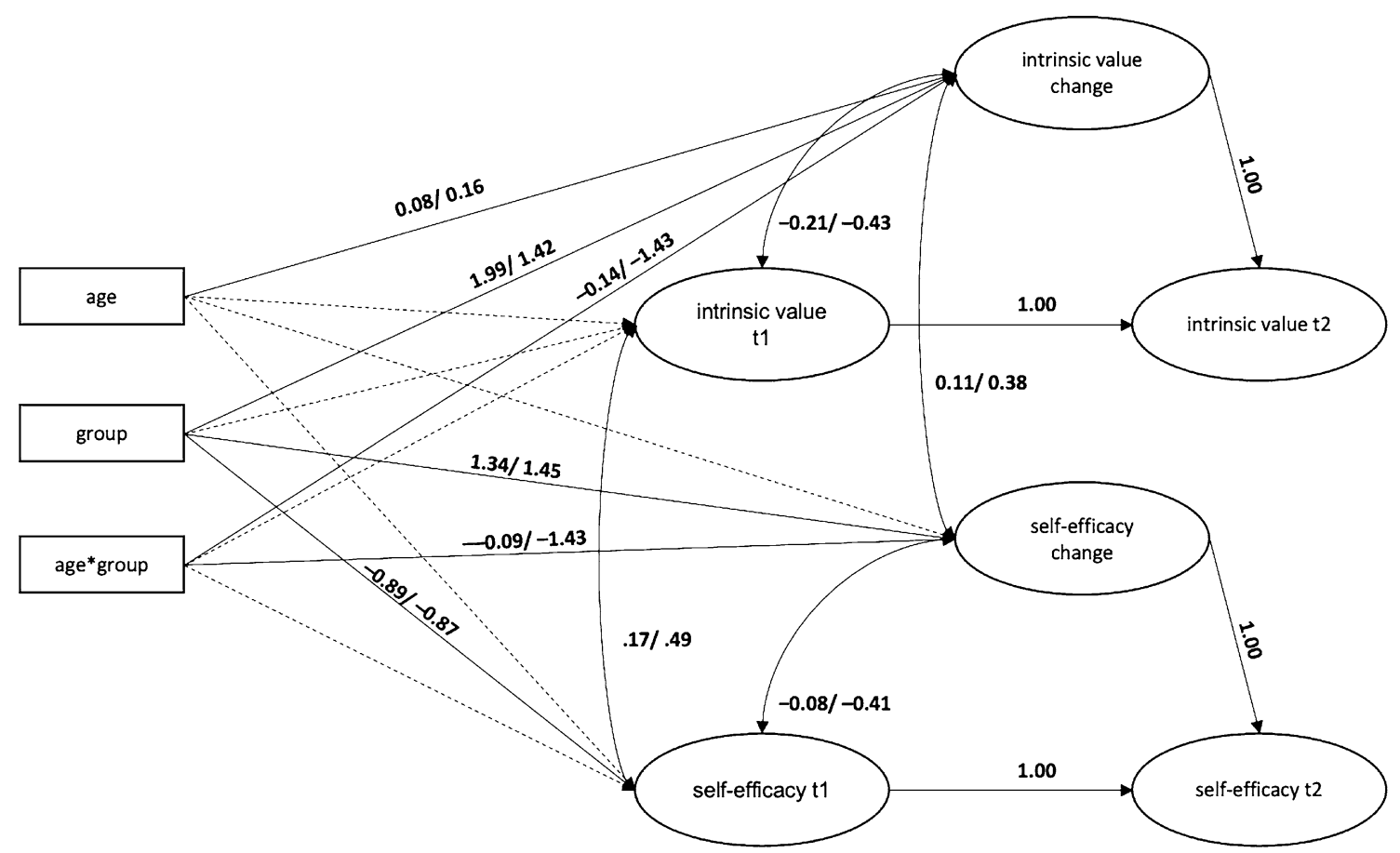

Fig. 2 Conditional latent change model with age, group variable and interaction term (age*group) as predictor variables of the development of self-efficacy and intrinsic value from $\mathrm{T} 1$ to $\mathrm{T} 2$. $\mathrm{T} 1=$ Time
1; T2 $=$ Time 2; Significant effects are shown as unstandardized coefficients $(B)$ in boldface and standardized coefficients $(\beta)$ in second position; solid pathways are significant at $p<0.05$
Fig. 3 Interaction of group and age on the change of intrinsic value from $\mathrm{T} 1$ to $\mathrm{T} 2$. SCL students from student-centered learning environments, $T D L$ students from teacher-directed learning environments

\section{interaction of learning environment and age on students' change of intrinsic value}

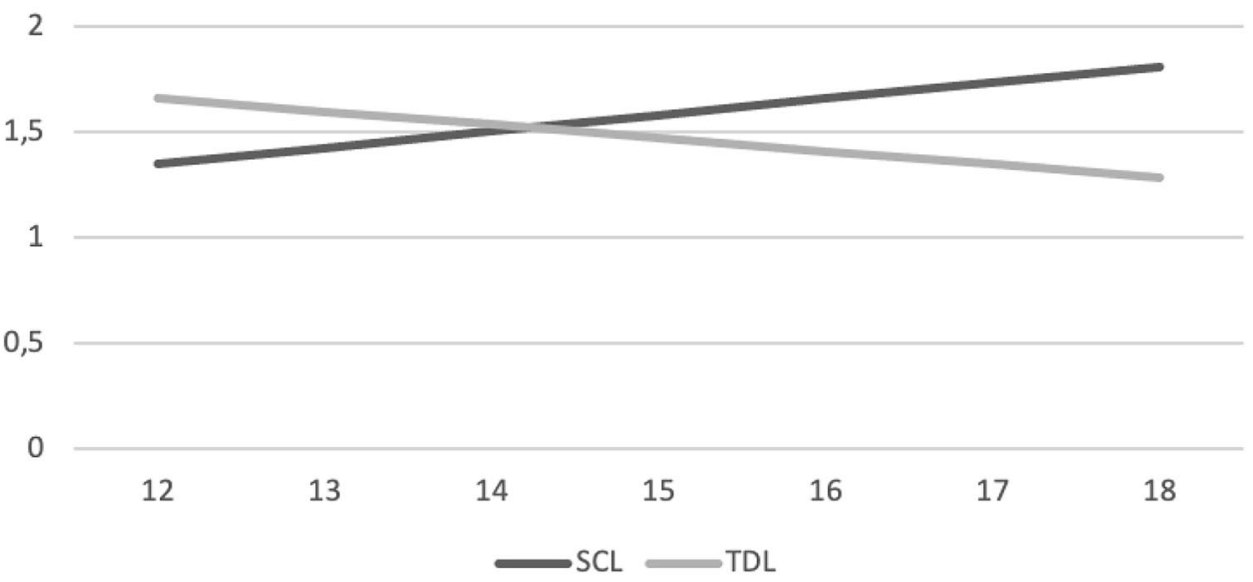

et al., 2020). The results based on the German PISA data from 2012 show that students in high-track schools report more interest in math and higher self-efficacy compared to students from all other school types (Schiepe-Tiska \& Schmidtner, 2013). Furthermore, Huang and O'Neil (1997) identified lower self-efficacy among students from low-track schools. Because our sample only consists of students from low- and mixed-track schools, one could assume floor effects because baseline levels of motivation are lower and are generally less prone to decline. Alternatively, these results could also indicate a stronger need to add covariates to the models. In the study conducted by Gnambs and Hanfstingl (2016), for example, intrinsic motivation did not decline after controlling for students' need support.

$\mathrm{H} 2$ was confirmed since developmental changes in students' self-efficacy are significantly associated with their changes in intrinsic value over the course of a school year. This finding is in line with the SEVT (Eccles \& Wigfield, 
Fig. 4 Interaction of group and age on the change of self-efficacyfrom $\mathrm{T} 1$ to T2. SCL students from student-centered learning environments, $T D L$ students from teacher-directed learning environments

\section{interaction of learning environment and age on students' change of self-efficacy}

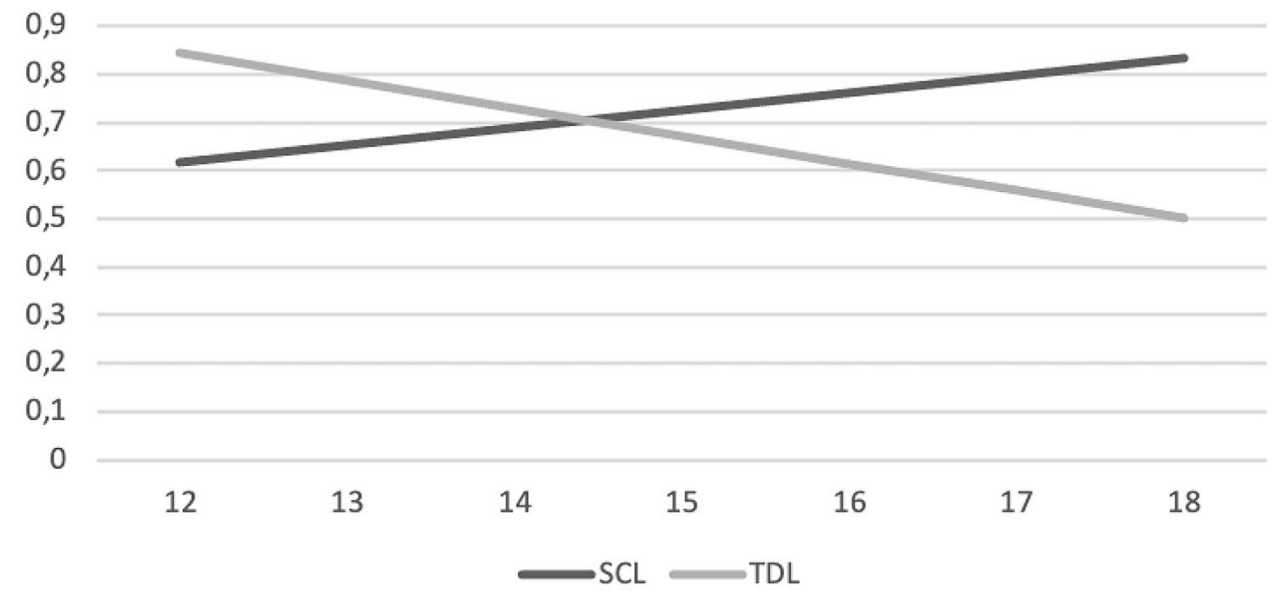

2020), which includes a reciprocal relationship between success expectancies (i.e., self-efficacy) and subjective task values (i.e., intrinsic value). Accordingly, studies have shown that self-efficacy and intrinsic value are positively associated (Brown, 2010; Bartimote-Aufflick et al., 2016). The result further supports Bandura's (1986) contention that self-efficacy acts as an intrinsic motivator.

H3 was partly confirmed since both age and group membership positively predict the change in intrinsic value. However, group membership (and not age) predicts the change in self-efficacy. More precisely, the older students get, the more changes (declines) in intrinsic value increase throughout a school year. While prior research has often demonstrated that grade 9 is the nadir of motivational decline (Fredricks \& Eccles, 2002; Watt, 2004), our findings indicate that this decline might continue in grade 10 , which was also found in a study of students from Austria (Gnambs \& Hanfstingl, 2016). Furthermore, the finding that age did not predict changes in self-efficacy supports research indicating that self-efficacy is more determined by environmental factors such as actual performances, learning environments, and social experiences (Schunk \& Meece, 2006). Accordingly, our results show that group membership positively predicts change in self-efficacy as well as change in intrinsic value. This means that students in TDL and SDL environments significantly differ in their change scores. This finding supports SEVT by highlighting the role of context in students' development of success expectancies and task values. It further supports research that has shown that the quality of the learning environment is essential for students' self-efficacy (Meece et al., 2003) and intrinsic motivation (Ryan \& Deci, 2017). Additionally, the next discussed results concerning $\mathrm{H} 4$ highlight the essential role of the learning environment since the motivational trajectories of students from SDL and TDL were completely opposite.
$\mathrm{H} 4$ proposed that the interaction of age and learning environment predicts motivational development throughout a school year. The results of the conditional latent change model support this hypothesis. Based on previous evidence (Schweder et al., 2019; Kulakow, 2020a), it was assumed that early adolescent students in particular benefit from the SDL environment. In accordance with SEVT (Eccles et al., 2020), it could be demonstrated that depending on the learning environment and age, students exhibit quite different motivational trajectories: while students from SDL demonstrated small decreases in early adolescence, older students in SDL reported increases during one school year. The early adolescent decreases might be a result of the double change situation: (1) change from primary school to secondary school and (2) change from TDL to SDL. SDL is characterized by high student responsibility, which students coming from TDL primary school environments are not used to. Students have to continuously monitor and plan their learning processes and have their progress reflected. While in conventional TDL environments learning goals for future months and years are hardly ever noticeable to students, the competency matrices in SDL make these goals transparent. Thus, the matrices also show all the learning goals for the future and consequently all the goals that students have not yet achieved. Especially in early adolescence, this transparency might add significant pressure to students paired with doubts about the feasibility of ever achieving all these goals. As students get older and shift into middle and late adolescence, the feasibility of achieving all goals might become recognizable for them, which might convey stronger feelings of control over their learning processes. Similarly, Meece and colleagues (2003) highlight the importance of such learning environments. According to their results, adolescents reported greater positive forms of motivation, such as self-efficacy, when schools and teachers emphasized 
student-directed teaching practices that were intellectually challenging and supportive of individual progress and mastery. These findings might further highlight the role of an ideal fit between students' prerequisites and the learning material and that they enjoy differentiated instruction. Regarding Bandura's (1997) sources of self-efficacy, enactive mastery experience is supposed be a major determinant of high self-efficacy. Differentiated instruction as provided by the SDL can thus support such enactive mastery experience.

Conversely, students from TDL exhibit relative increases in intrinsic value and self-efficacy in early adolescence, while older students in TDL report decreases. For the latter, the approaching end of secondary education and upcoming examinations might equally create additional stress and pressure that might negatively affect their motivation (Raufelder et al., 2018). Additionally, considering the premises of stageenvironment fit theory, it is perhaps no wonder that we continuously see those motivational declines: While students in adolescence continuously strive for more autonomy in their lives, conventional TDL environments often do too little to satisfy adolescents' needs, such as their need for autonomy (Deci \& Ryan, 2000). On the contrary, after the transition to secondary schools, students face continuous summative assessments, whole-class instruction, a focus on normative comparisons instead of a focus individual development. The findings for TDL students further support SEVT (Eccles \& Wigfield, 2020) by showing that this learning environment does not meet the needs of developing adolescents such as growing autonomy, more control over their lives, and independent decision making (see Rosenzweig et al., 2019). Accordingly, this learning environment negatively impacts many students' expectancies and values.

Overall, the present study contributes to empirical research on the recently reformulated SEVT (Eccles \& Wigfield, 2020). The results support the essential role of the learning environment for students' expectancies and values for academic tasks and areas and as such for their motivation in school. More precisely, it has been shown that students in SDL have a more positive motivational development in the long term except for a decline after school transition accompanied by a change from TDL to SDL. Put simply, a higher degree of student directedness and room for decision making might be important for motivational trajectories.

\section{Strengths, limitations, and future directions}

The present study contributes to an important body of research on motivational trajectories. Not only do longitudinal studies like this one show how misleading conventional mean comparisons can be (Kulakow \& Raufelder, 2020), it exhibits that learning environments may have distinct influences on adolescents' motivational development and that certain environmental preconditions may potentially counteract the regularly shown motivational declines that emerge in early adolescence and reach their peak in middle adolescence. These results additionally suggest that educational practice should strive for continuously adding more room for decision-making to learning environments, because these are assumingly more appropriate for adolescents' development in a time, in which they consistently strive for more autonomy in their lives (Eccles \& Midgley, 1989).

However, it is limited because it includes only two measurement points, which are not able to identify long-term trajectories over different school years. Furthermore, the study is based on data from students from low-track and mixed-track schools because SDL in high-track schools in Germany is still rare. This study is further limited by using an instrument measuring "intrinsic motivation" instead of "intrinsic value". Although there is a conceptual overlap between both constructs, readers should be aware that both concepts are based on different theoretical perspectives (Eccles \& Wigfield, 2020). Future studies that directly assess "intrinsic value" could contribute to verify or falsify the present findings. Additionally, the present study only considered one of the four subjective task values proposed by SEVT. Lastly, particularly because this article demands more detailed inspection of motivational trajectories in contrast to simply comparing mean values, it should be noted that it completely disregards motivational development during summer holidays, although they have already been shown to be relevant for other variables, such as achievement (Cooper et al., 1996).

Besides these limitations, the present study demonstrates that different learning environments affect not only baseline motivation but also its development during one school year for different age groups in adolescence. Future studies with more equally distributed samples and a longitudinal design over different school years should extend this line of research, particularly with a focus on controlling for more classroom- (e.g., goal structures) and teacher-related variables (e.g., teacher self-efficacy, socializers' beliefs). Such investigations could not only substantiate the findings of this study but also provide further evidence of more distal assumptions of SEVT that have not lately been the focus of research (Eccles \& Wigfield, 2020).

Funding Open Access funding enabled and organized by Projekt DEAL.

Open Access This article is licensed under a Creative Commons Attribution 4.0 International License, which permits use, sharing, adaptation, distribution and reproduction in any medium or format, as long as you give appropriate credit to the original author(s) and the source, provide a link to the Creative Commons licence, and indicate if changes were made. The images or other third party material in this article are 
included in the article's Creative Commons licence, unless indicated otherwise in a credit line to the material. If material is not included in the article's Creative Commons licence and your intended use is not permitted by statutory regulation or exceeds the permitted use, you will need to obtain permission directly from the copyright holder. To view a copy of this licence, visit http://creativecommons.org/licenses/by/4.0/.

\section{References}

American Psychological Association. (2002). Ethical principles of psychologists and code of conduct. American Psychologist, 57(12), 1060-1073. https://doi.org/10.1037/0003-066X.57.12.1060

Anderman, E., Maehr, M.L., Midgley, C. (1999). Declining motivation after the transition to middle school: Schools can make a difference. Journal of Research \& Development in Education.

Baeten, M., Kyndt, E., Struyven, K., \& Dochy, F. (2010). Using student-centred learning environments to stimulate deep approaches to learning: Factors encouraging or discouraging their effectiveness. Educational Research Review, 5(3), 243-260. https://doi. org/10.1016/j.edurev.2010.06.001

Bandura, A. (1986). Social foundations of thought and action: A social cognitive theory. Prentice-Hall.

Bandura, A. (1997). Self-efficacy: The exercise of control. Freeman.

Bardach, L., Popper, V., Hochfellner, E., \& Lüftenegger, M. (2019). Associations between vocational students' perceptions of goal structures, mastery goals, and self-efficacy in five subjectspractical relevance as a potential mediator. Empirical Research in Vocational Education and Training. https://doi.org/10.1186/ s40461-019-0084-0

Bardach, L., Yanagida, T., Lüftenegger, M., \& Bardach, L. (2020). Studying classroom climate effects in the context of multi-level structural equation modelling : an application-focused theoretical discussion and empirical demonstration discussion and empirical demonstration. International Journal of Research \& Method in Education, 43(4), 348-363. https://doi.org/10.1080/1743727X. 2020.1791071

Bartimote-Aufflick, K., Bridgeman, A., Walker, R., Sharma, M., \& Smith, L. (2016). The Study, evaluation, and improvement of university student self-efficacy. Studies in Higher Education, 41(11), 1918-1942. https://doi.org/10.1080/03075079.2014.999319

Benita, M., Roth, G., \& Deci, R. (2014). When are mastery goals more adaptive? It depends on experiences of autonomy support and autonomy. Journal of Educational Psychology, 106(1), 258-267. https://doi.org/10.1037/a0034007

Benjamini, Y., \& Hochberg, Y. (1995). Controlling the false discovery rate: A practical and powerful approach to multiple testing. Journal of the Royal Statistical Society: Series B, 57(1), 289-300. https://doi.org/10.1111/j.2517-6161.1995.tb02031.x

Benware, C., \& Deci, E. L. (1984). The quality of learning with an active versus passive motivational set. American Educational Research Journal, 21(4), 755-765. https://doi.org/10.3102/00028 312021004755

Bong, M., \& Skaalvik, E. M. (2003). Academic self-concept and selfefficacy: How different are they really? Educational Psychology Review, 15(1), 1-40. https://doi.org/10.1023/a:1021302408382

Brown, B. L. (2010). The impact of self-efficacy and motivation characteristics on the academic achievement of upward bound participants. (Unpublished doctoral dissertation). University of Southern Mississippi, Hattiesburg, MS.

Brown, T. A. (2015). Confirmatory factor analysis for applied research (2nd ed.). Guilford.
Chen, F. F. (2007). Sensitivity of goodness of fit indexes to lack of measurement invariance. Structural Equation Modeling A: Multidisciplinary Journal, 14(3), 464-504. https://doi.org/10.1080/ 10705510701301834

Chorzempa, B. F., \& Graham, S. (2006). Primary-grade teachers' use of within-class ability grouping in reading. Journal of Educational Psychology, 98(3), 529-541. https://doi.org/10.1037/0022-0663. 98.3.529

Collie, R. J., \& Martin, A. J. (2017). Adaptive and maladaptive workrelated motivation among teachers: A person-centered examination and links with well-being. Teaching and Teacher Education, 64, 199-210. https://doi.org/10.1016/j.tate.2017.02.010

Cooper, H., Nye, B., Charlton, K., Lindsay, J., \& Greathouse, S. (1996). The effects of summer vacation on achievement test scores: A narrative and meta-analytic review. Review of Educational Research, 66(3), 227-268. https://doi.org/10.3102/00346543066003227

Corpus, J. H., McClintic-Gilbert, M. S., \& Hayenga, A. O. (2009). Within-year changes in children's intrinsic and extrinsic motivational orientations: Contextual predictors and academic outcomes. Contemporary Educational Psychology, 34(2), 154-166. https:// doi.org/10.1016/j.cedpsych.2009.01.001

De Caroli, M. E., \& Sagone, E. (2014). Generalized self-efficacy and well-being in adolescents with high vs. low scholastic self-efficacy. Procedia - Social and Behavioral Sciences, 141, 867-874. https://doi.org/10.1016/j.sbspro.2014.05.152

Deci, E. L., \& Ryan, R. M. (1985). Intrinsic motivation and selfdetermination in human behavior. Springer.

Deci, E. L., \& Ryan, R. M. (2000). The "What" and "Why" of goal pursuits: Human needs and the self-determination of behavior. Psychological Inquiry, 11(4), 227-268. https://doi.org/10.1207/ s15327965pli1104_01

Eccles, J.S. (1993). School and family effects on the ontogeny of children's interests, self-perceptions, and activity choices. In J. Jacobs (Ed.), Nebraska Symposium on Motivation, 1992: Developmental perspectives on motivation (pp. 145-208). University of Nebraska Press.

Eccles, J. S., Lord, S., \& Midgley, C. (1991). What are we doing to early adolescents? The impact of educational contexts on early adolescents. American Journal of Education, 99(4), 521-542. https://doi.org/10.1086/443996

Eccles, J. S., \& Midgley, C. (1989). Stage-environment fit: Developmentally appropriate classrooms for young adolescents. In C. Ames \& R. Ames (Eds.), Research on motivation in education (Vol. 3, pp. 139-186). Academic Press.

Eccles, J. S., \& Wigfield, A. (2020). From expectancy-value theory to situated expectancy-value theory: A developmental, social cognitive, and sociocultural perspective on motivation. Contemporary Educational Psychology. https://doi.org/10.1016/j. cedpsych.2020.101859

Fredricks, J. A., \& Eccles, J. S. (2002). Children's competence and value beliefs from childhood through adolescence: growth trajectories in two male-sex-typed domains. Developmental Psychology, 38(4), 519-533. https://doi.org/10.1037/0012-1649. 38.4.519

Gnambs, T., \& Hanfstingl, B. (2016). The decline of academic motivation during adolescence: An accelerated longitudinal cohort analysis on the effect of psychological need satisfaction. Educational Psychology, 36(9), 1691-1705. https://doi.org/10.1080/01443410. 2015.1113236

Hattie, J. (2009). Visible learning: A synthesis of over 800 meta-analyses relating to achievement. Routledge.

Hoigaard, R., Kovac, V. B., Overby, N. C., \& Haugen, T. (2015). Academic self-efficacy mediates the effects of school psychological climate on academic achievement. School Psychology Quarterly, 30(1), 64-74. https://doi.org/10.1037/spq0000056 
Hox, J. J. (2002). Multilevel analysis: Techniques and applications. Lawrence Erlbaum Associates.

Hu, L. T., \& Bentler, P. M. (1999). Cutoff criteria for fit indexes in covariance structure analysis: Conventional criteria versus new alternatives. Structural Equation Modeling: A Multidisciplinary Journal, 6(1), 1-55. https://doi.org/10.1080/10705519909540118

Huang, D., \& O'Neil, H. F. (1997). The role of parental expectation, effort, and self-efficacy in the achievement of high and low track high school students in Taiwan. In Paper presented at the Annual Meeting of the American Educational Research Association, Chicago, IL

Jerusalem, M., \& Schwarzer, R. (1999). Skalen zur Erfassung von lehrer- und Schülermerkmalen: Dokumentation der psychometrischen Verfahren im Rahmen der wissenschaftlichen Begleitung des Modellversuchs selbstwirksame Schulen [Scales to assess teacher and students characteristics: Documentation of the psychometric procedures in the context of the scientific monitoring of the pilot scheme for self-effective schools]. Berlin, Germany: Freie Universität Berlin.

Kitsantas, A., \& Zimmerman, B. J. (2008). College students' homework and academic achievement: The mediating role of selfregulatory beliefs. Metacognition and Learning, 4(2), 97-110. https://doi.org/10.1007/s11409-008-9028-y

Kline, R. B. (2016). Principles and practice of structural equation modeling (4th ed.). Guilford Press.

Knowles, M. (1975). Self-directed learning: A guide for learners and teachers. Association Press.

Kolić-Vehovec, S., Rončević, B., \& Bajšanski, I. (2008). Motivational components of self-regulated learning and reading strategy use in university students: The role of goal orientation patterns. Learning and Individual Differences, 18(1), 108-113. https://doi.org/10.1016/j.lindif.2007.07.005

Kulakow, S. (2020). How autonomy support mediates the relationship between self-efficacy and approaches to learning. The Journal of Educational Research. https://doi.org/10.1080/00220671. 2019.1709402

Kulakow, S. (2020). Academic self-concept and achievement motivation among adolescent students in different learning environments: Does competence-support matter? Learning and Motivation. https://doi.org/10.1016/j.1mot.2020.101632

Kulakow, S., \& Raufelder, D. (2020). Enjoyment benefits adolescents' self-determined motivation in student-centered learning. International Journal of Educational Research. https://doi.org/ 10.1016/j.ijer.2020.101635

Lazarides, R., Dicke, A.-L., Rubach, C., \& Eccles, J. S. (2019). Profiles of motivational beliefs in math: Exploring their development, relations to student-perceived classroom characteristics, and impact on future career aspirations and choices. Journal of Educational Psychology. https://doi.org/10.1037/edu0000368

Lazarides, R., Dietrich, J., \& Taskinen, P. H. (2019). Stability and change in students' motivational profiles in mathematics classrooms: The role of perceived teaching. Teaching and Teacher Education, 79, 164-175. https://doi.org/10.1016/j.tate.2018.12.016

Lesmond, G., McCahan, S., Beach, D. (2017). Development of analytic rubrics for competency assessment. Higher Education Quality Council of Ontario.

Little, R. J. A., \& Rubin, D. B. (1987). Statistical analysis with missing data. Wiley.

Little, R. J. A., \& Rubin, D. B. (1989). The analysis of social science data with missing values. Sociological Methods and Research, 18, 292-326.

Lüdtke, O., Marsh, H. W., Robitzsch, A., Trautwein, U., Asparouhov, T., \& Muthen, B. (2008). The multilevel latent covariate model: A new, more reliable approach to group-level effects in contextual studies. Psychol Methods, 13(3), 203-229. https://doi.org/ 10.1037/a0012869
Marsh, H.W., Hau, K.-T., Grayson, D. (2005). Goodness of fit evaluation in structural equation modeling. In A. Maydeu-Olivares, \& J. McArdle (Eds.). Contemporary Psychometrics: A festschrift for Roderick P. McDonald (pp. 275-340). Mahwah, NJ: Erlbaum.

Marsh, H. W., Lüdtke, O., Nagengast, B., Trautwein, U., Morin, A. J. S., Abduljabbar, A. S., \& Köller, O. (2012). Classroom climate and contextual effects: conceptual and methodological issues in the evaluation of group-level effects. Educational Psychologist, 47(2), 106-124. https://doi.org/10.1080/00461520.2012.670488

McArdle, J. J. (2009). Latent variable modeling of differences in changes with longitudinal data. Annual Review of Psychology, 60, 577-605. https://doi.org/10.1146/annurev.psych.60.110707. 163612

McArdle, J. J., \& Hamagami, F. (2001). Latent difference score structural models for linear dynamic analyses with incomplete longitudinal data. In L. M. Collins \& A. G. Sayer (Eds.), Decade of behavior. New methods for the analysis of change (pp. 139-175). American Psychological Association.

Meece, J. L., Herman, P., \& McCombs, B. L. (2003). Relations of learner-centered teaching practices to adolescents' achievement goals. International Journal of Educational Research, 39(4-5), 457-475. https://doi.org/10.1016/j.ijer.2004.06.009

Miyamoto, A., Murayama, K., \& Lechner, C. M. (2020). The developmental trajectory of intrinsic reading motivation: Measurement invariance, group variations, and implications for reading proficiency. Contemporary Educational Psychology, 63, 101921. https://doi.org/10.1016/j.cedpsych.2020.101921

Morin, A. J. S., Marsh, H. W., Nagengast, B., \& Scalas, L. F. (2014). Doubly latent multilevel analyses of classroom climate: An illustration. Journal of Experimental Education, 82(2), 143-167. https://doi.org/10.1080/00220973.2013.769412

Müller, F. H., Hanfstingl, B., \& Andreitz, I. (2007). Skalen zur motivationalen Regulation beim Lernen von Schülerinnen und Schülern: Adaptierte und ergänzte Version des Academic Self-Regulation Questionnaire (SRQ-A) nach Ryan \& Connell [Scales for motivational regulation in the learning of pupils: Adapted and supplemented version of the Academic Self-Regulation Questionnaire (SRQ-A) according to Ryan \& Connell]. Klagenfurth, Austria: Alpen-Adria-Universität.

Muthén, L. K., \& Muthén, B. O. (1998-2017). Mplus user's guide ( $8^{\text {th }}$ ed.). Muthén \& Muthén.

Niemiec, C. P., \& Ryan, R. M. (2009). Autonomy, competence, and relatedness in the classroom: Applying self-determination theory to educational practice. Theory and Research in Education, 7(2), 133-144. https://doi.org/10.1177/1477878509104318

Otis, N., Grouzet, F. M. E., \& Pelletier, L. G. (2005). Latent Motivational Change in an Academic Setting: A 3-Year Longitudinal Study. Journal of Educational Psychology, 97(2), 170-183. https://doi.org/10.1037/0022-0663.97.2.170

Pianta, R. C., Hamre, B., \& Stulman, M. (2003). Relationships between teachers and children. Wiley.

Raufelder, D., Lazarides, R., \& Lätsch, A. (2018). How classmates' stress affects student's quality of motivation. Stress \& Health, 34(5), 649-662. https://doi.org/10.1002/smi.2832

Raufelder, D., \& Ringeisen, T. (2016). Self-perceived competence and test anxiety: The role of academic self-concept and self-efficacy. Journal of Individual Differences, 37, 159-167. https://doi.org/ 10.1027/1614-0001/a000202

Reeve, J., \& Lee, W. (2014). Students' classroom engagement produces longitudinal changes in classroom motivation. Journal of Educational Psychology, 106(2), 527-540. https://doi.org/10.1037/ a0034934

Rosenzweig, E. Q., Wigfield, A., \& Eccles, J. S. (2019). Expectancyvalue theory and its relevance for student motivation and learning. In K. A. Rennninger, \& S. E. Hidi (Eds.), The Cambridge 
handbook of motivation and learning (pp. 617-644). Cambridge University Press. https://doi.org/10.1017/9781316823279.026

Rossi, T., Trevisol, A., Santos-nunes, D., Dapieve-patias, N., Hohendorff, J. Von, Santos-nunes, D. (2020). Perceived overall selfefficacy and motivation to learn in high school teenagers. Acta Colombiana de Psicología, 23(1), 254-263. https://doi.org/https:// doi.org/10.14718/acp.2020.23.1.12

Rubin, D. B. (1987). Multiple imputation for nonresponse in surveys. Wiley.

Ryan, R. M., \& Connell, J. M. (1989). Perceived locus of causality and internalization: Examining reasons for acting in two domains. Journal of Personality and Social Psychology, 57(5), 749-761. https://doi.org/10.1037/0022-3514.57.5.749

Ryan, R. M., \& Deci, E. L. (2000). Self-determination theory and the facilitation of intrinsic motivation, social development, and wellbeing. American Psychologist, 55(1), 68-78. https://doi.org/10. 1037//0003-066x.55.1.68

Ryan, R.M., \& Deci, E.L. (2017). Self-determination theory: Basic psychological needs in motivation, development, and wellness. Guilford.

Salami, S., \& Ogundokun, M. (2009). Emotional intelligence and academic self-efficacy as predictors of academic performance among senior secondary school students in Oyo state, Nigeria. Perspectives in Education, 25(3), 175-185.

Satorra, A., \& Bentler, P. (2001). A scales difference chi-square test statistic for moment structure analysis. Psychometrika, 66(4), 507-514. https://doi.org/10.1007/bf02296192

Schafer, J. L., \& Graham, J. W. (2002). Missing data: Our view of the state of the art. Psychological Methods, 7(2), 147-177. https://doi. org/10.1037/1082-989x.7.2.147

Schaffner, E., Philipp, M., \& Schiefele, U. (2016). Reciprocal effects between intrinsic reading motivation and reading competence? A cross-lagged panel model for academic track and nonacademic track students. Journal of Research in Reading, 39(1), 19-36. https://doi.org/10.1111/1467-9817.12027

Schiepe-Tiska, A., \& Schmidtner, S. (2013). Mathematikbezogene emotionale und motivationale Orientierungen, Einstellungen und Verhaltensweisen von Jugendlichen in PISA 2012. In M. Prenzel, C. Sälzer, E. Klieme, \& O. Köller (Eds.), PISA 2012. Fortschritte und Herausforderungen in Deutschland (pp. 99-122). Waxmann.

Schnell, K., Ringeisen, T., Raufelder, D., \& Rohrmann, S. (2015). The impact of adolescents' self-efficacy and self-regulated goal attainment processes on school performance - Do gender and test anxiety matter? Learning and Individual Differences, 38, 90-98. https://doi.org/10.1016/j.lindif.2014.12.008

Schunk, D.H., \& Meece, J.L. (2006). Self-efficacy development in adolescents. In F. Pajares \& T. Urdan (Eds.), Self-efficacy beliefs in adolescents (pp. 71-96). Information Age.

Schweder, S. (2019). Mastery goals, positive emotions and learning behavior in self-directed vs. teacher-directed learning. European Journal of Psychology of Education. https://doi.org/10.1007/ s10212-019-00421-z

Schweder, S., \& Raufelder, D. (2021). Interest and learning strategies. The moderating function of flow in self-directed vs. teacherdirected learning. The Journal of Educational Research, 88, 1-15. https://doi.org/10.1080/00220671.2021.1887066

Schweder, S., \& Raufelder, D. (2021). Needs satisfaction and motivation among adolescent boys and girls during self-directed learning intervention. Journal of Adolescence, 88, 1-15. https://doi.org/10. 1016/j.adolescence.2021.01.007

Schweder, S., Raufelder, D., Kulakow, S., \& Wulff, T. (2019). How the learning context affects adolescents' goal orientation, effort, and learning strategies. Journal of Educational Research, 112(5), 604-614. https://doi.org/10.1080/00220671.2019.1645085

Schweder, S., Raufelder, D., \& Wulff, T. (2020). Adolescents' goals, self-efficacy, and positive emotions - how important is the learning context? International Journal of School \& Educational Psychology. https://doi.org/10.1080/21683603.2020.1791771

Schweizer, K. (2010). Some guidelines concerning the modeling of traits and abilities in test construction. European Journal of Psychological Assessment, 26, 1-2. https://doi.org/10.1027/10155759/a000001

Shell, D. F., Colvin, C., \& Bruning, R. H. (1995). Self-efficacy, attribution, and outcome expectancy mechanisms in reading and writing achievement: grade-level and achievement-level differences. Journal of Educational Psychology. https://doi.org/10.1037/00220663.87.3.386

Stevens, D.D., Levi, A.J., \& Walvoord, B.E. (2013). Introduction to rubrics: An assessment tool to save grading time, convey effective feedback, and promote student learning (2nd ed.). Stylus Publishing.

Steyer, R., Eid, M., \& Schwenkmezger, P. (1997). Modeling true intraindividual change: True change as a latent variable. Methods of Psychological Research Online, 2(1), 21-33.

Steyer, R., Partchev, I., \& Shanahan, M. (2000). Modeling true intraindividual change in structural equation models: The case of poverty and children's psychosocial adjustment. In T. D. Little, K. U. Schnabel, \& J. Baumert (Eds.), Modeling longitudinal and multiple-group data: Practical issues, applied approaches, and specific examples (pp. 109-126). Erlbaum.

Tang, N., Yi, Y., \& Westwood, P. (2007). Worry, general self-efficacy and school achievement: An exploratory study with chinese adolescents. Australian Journal of Guidance and Counselling, 17(1), 68-80. https://doi.org/10.1375/ajgc.17.1.68

Urdan, T., \& Midgley, C. (2003). Changes in the perceived classroom goal structure and pattern of adaptive learning during early adolescence. Contemporary Educational Psychology, 28(4), 524-551. https://doi.org/10.1016/S0361-476X(02)00060-7

Vansteenkiste, M., Simons, J., Lens, W., Sheldon, K. M., \& Deci, E. L. (2004). Motivating learning, performance, and persistence: The synergistic effects of intrinsic goal contents and autonomysupportive contexts. Journal of Personality and Social Psychology, 87(2), 246-260. https://doi.org/10.1037/0022-3514.87.2.246

Vygotsky, L.S. (1978). Mind in society (4th rev.). Harvard University Press.

Watt, H. M. (2004). Development of adolescents' self-perceptions, values, and task perceptions according to gender and domain in 7ththrough 11th-grade Australian students. Child Development, 75(5), 1556-1574. https://doi.org/10.1111/j.1467-8624.2004.00757.x

West, S. G., Taylor, A. B., \& Wu, W. (2012). Model fit and model selection in structural equation modeling. In R. H. Hoyle (Ed.), Handbook of structural equation modeling (pp. 209-231). Guilford Press.

Wigfield, A., \& Eccles, J. S. (2020). 35 years of research on students' subjective task values and motivation: A look back and a look forward. In A. J. Elliot (Ed.), Advances in motivation science (pp. 161-198). Elsevier. https://doi.org/10.1016/bs.adms.2019.05.002

Zimmerman, B. J. (1997). Self efficacy and educational development. In A. Bandura (Eds.), Self-efficacy in changing societies (pp. 202-231). Cambridge University Press.

Zimmerman, B. J. (2000). Attaining self-regulation: A social cognitive perspective. In M. Boekaerts, P. R. Pintrich \& M. Zeidner (Eds.), Handbook of self-regulation (pp. 13-40). Academic Press.

Zimmerman, B. J., \& Martinez-Pons, M. (1990). Student differences in self-regulated learning: Relating grade, sex, and giftedness to self-efficacy and strategy use. Journal of Educational Psychology, 82(1), 51-59. https://doi.org/10.1037/0022-0663.82.1.51

Publisher's Note Springer Nature remains neutral with regard to jurisdictional claims in published maps and institutional affiliations. 